\title{
A PHOTOELECTRIC PHOTOMETER FOR EXTENDED SOURCES
}

\author{
D. Malaise \\ (Institut d'Astrophysique de l'Université de Liège, Belgique)
}

\section{ABST RACT}

The paper describes a photoelectric photometer especially designed for extended sources. Six bands selected by a concave grating spectrograph can be measured simultaneously. The sensitivity commutation of the electrometers is automatic and a $10^{\prime}$ field can be observed during measurements.

\section{RÉSUMÉ}

Nous décrivons un photomètre photoélectrique spécialement conçu pour l'observation des sources étendues. On peut effectuer les mesures simultanément dans six bandes sélectionnées au moyen d'un spectrographe à réseau concave. La commutation de sensibilité des électromètres se fait automatiquement. Un champ de $10^{\prime}$ peut être observé sans interrompre les mesures.

Two years ago, Professor Swings asked me to design and build a photometer for studying the monochromatic photometric profile of comets. The instrument is especially suited for the study of extended sources with emission spectra. It will be used to measure the monochromatic surface brightnesses of planetary nebulae and precise ratios of line intensities in different parts of the nebulae.

The instrument is designed as a concave grating spectrograph (Figure 1). A small circular diaphragm, defining the element of resolution in the field of view, is placed on the Rowland circle of the grating at $32^{\circ}$ incidence angle. The grating has a radius of

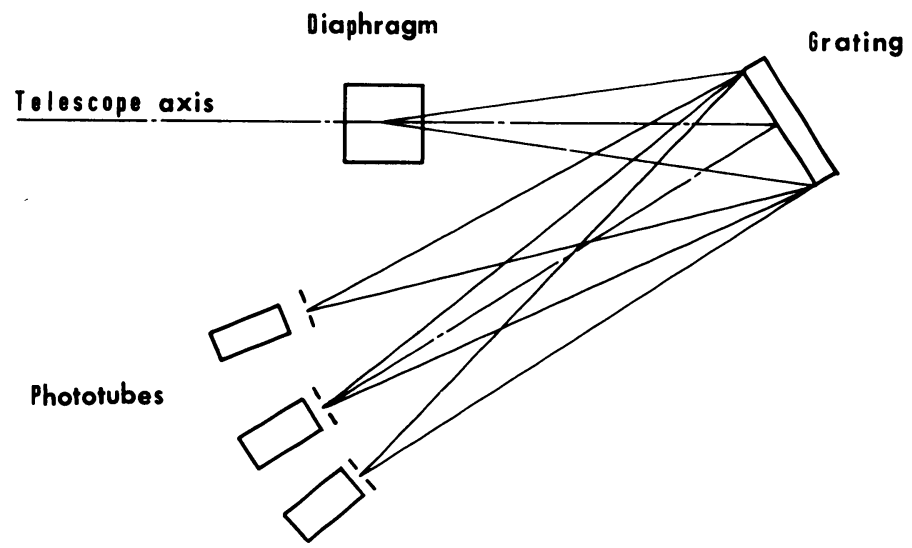

FIG. 1. Schematic optical design of the spectrograph. 
$750 \mathrm{~mm}$ and is ruled at 982 grooves $/ \mathrm{mm}$ with a blaze angle of $18^{\circ} 03^{\prime}$ (Bausch \& Lomb no. 35-52-15-65). The bands to be measured are selected by a series of adjustable slits movable on the Rowland circle. A very compact design of the mountings supporting the slits and the photomultiplier tubes enables one to select two adjacent bands only $300 \AA$ (150 $\AA$ in the second order) apart. For reasons of compactness, we have adopted ASCOP 541A and 541E photomultiplier tubes. The dispersion is $14 \AA / \mathrm{mm}$ in the first order (blazed wavelength $6200 \AA$ ), and $7 \AA / \mathrm{mm}$ in the second order (blazed wavelength $3100 \AA$ ). The bands falling between $4000 \AA$ and $8500 \AA$ are picked up in the first order, while those corresponding to wavelengths between $3000 \AA$ and $4000 \AA$ are picked up in the second order. The diffraction angles are between $+13^{\circ}$ and $-8^{\circ}$, which makes astigmatism nearly constant over the whole range.

The choice of the bands is very versatile and we can select any band-pass up to $70 \AA$ at any place in the range $3000 \AA$ to $8500 \AA$. The minimum width of the bands depends on the size of the entrance diaphragm and on the diffraction order. Typically, with an entrance diaphragm of $1 \mathrm{~mm}$ diameter and working in the first order, the minimum band-pass is $14 \AA$. The width of the band is set within $0 \cdot 1 \AA$ with the help of a microscope sliding in the phototube attachment in place of the phototube, and then the slit mounting is set on the Rowland circle within $0.5 \AA$ by displacing and adjusting the mounting on the circle with respect to a calibration line delivered by the spectrograph. It is possible to work with six bands simultaneously without overcrowding the Rowland circle.

The instrument has been constructed to work at the Cassegrain focus of the 193-cm telescope of the Haute-Provence Observatory. The relative aperture is $F: 15$ and the field scale $7 " / \mathrm{mm}$. We have three easily interchangeable entrance diaphragms of $0 \cdot 5,1$ and $2 \mathrm{~mm}$ diameter respectively. As shown in Figure 2 the entrance diaphragm is at the centre of a large diagonal mirror which folds the field rays to the field viewer. The image of a $10^{\prime}$ field is formed on a reticle, where it is observed through the eyepiece without interrupting the measurements.

Since we are operating with six channels simultaneously, we had to provide for

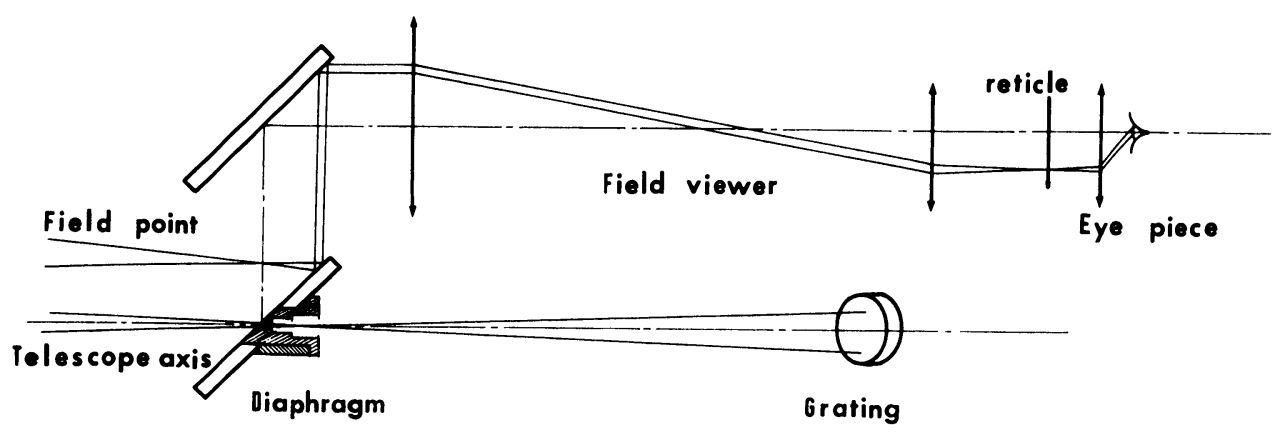

FIG. 2. Schematic optical design of the field viewer. 
automatic commutation of the sensitivity of the electrometers. Each electrometer is equipped with a high-level and a low-level sensor, which actuate a synchronous two-way counter; the latter selects the input resistor and gain appropriate to the signal. The electrometer has been completely designed and constructed in our electronic shop. Its final form is a compact $18 \times 20 \times 7 \mathrm{~cm}$ module with an 'automaticmanual' switch and an external display of the operating range. We have chosen a $10^{1 / 2}$ ratio between the 8 sensitivities which gives us a 4-decade total capacity. We have 6 of these electrometers mounted in an 8-case box attached directly onto the photometer. The seventh case of the box is used for interconnection of power supplies, and the last one is used to control the temperature of the whole box to within $1{ }^{\circ} \mathrm{C}$.

The data are recorded on 6 paper chart recorders, but we plan to add an analog-todigital converter-multiplexer and a magnetic tape recorder after the electronics have been tested in their classical form.

When the instrument is attached to the 193-cm telescope, a signal-to-noise ratio of one corresponds to a flux onto the primary mirror of $5 \times 10^{-14} \mathrm{erg} \mathrm{cm}^{-2} \mathrm{~s}^{-1}$ at $4200 \AA$, and $6 \times 10^{-13} \mathrm{erg} \mathrm{cm}^{-2} \mathrm{~s}^{-1}$ at $7300 \AA$. 